

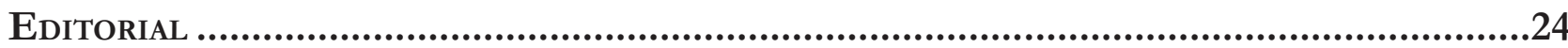

O Direito na fronteira da razão: Psicologia, neurociência e economia comportamental................... 24 Patrícia Perrone Campos Mello e Sergio Nojiri

I. NeURodireito: COGNIÇão, EMOÇÃo, JUÍZOS MORAIS E CIÊNCIA ..........................................26

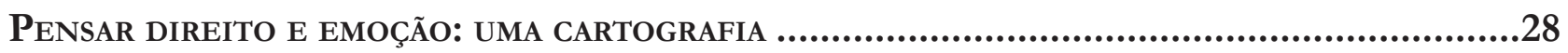

Nevita Maria Pessoa de Aquino Franca Luna

Neurodireito: o início, o fim E O MEIO

Carlos Marden e Leonardo Martins Wykrota

ENSAIO JURÍDICO SOBRE A RACIONALIDADE HUMANA: MAIORES, CAPAZES E IRRACIONAIS

André Perin Schmidt Neto e Eugênio Facchini Neto

DIVERGÊNCIAS DE PRINCÍPIO: ARGUMENTOS JURÍDICOS E MORAIS EM UM CENÁRIO DE DESACORDOS SOCIAIS

André Matos de Almeida Oliveira, Pâmela de Rezende Côrtes e Leonardo Martins Wykrota

CONSILIÊNCIA E A POSSIBILIDADE DO NEURODIREITO: DA DESCONFIANÇA À RECONCILIAÇÃO DISCIPLINAR.....

Thaís de Bessa Gontijo de Oliveira e Renato César Cardoso

MODELOS DE MORALIDADE

Molly J. Crockett

A INFELIZ BUSCA POR FELICIDADE No DiREITo

Úrsula Simões da Costa Cunha Vasconcellost, Noel Struchiner e Ivar Hannikainen

Além da liberdade: PersPeCtivas Em Nietzsche.

Lucas Costa de Oliveira

A mediaÇão de CONFlitos SOb a PERSPECTIVA do DESENVOLVIMENTO HUMANO: AS CONTRIBUIÇÕES DA PSICOLOGIA POSITIVA

Simone de Biazzi Ávila Batista da Silveira e Deise Brião Ferraz

Neuroimagiologia e aValiação de ResPonsabilidade

Nicole A. Vincent 
ANÁLISE CRÍTICA DA ORIENTAÇÃO DE CIDADÃOS COMO MÉTODO PARA OTIMIZAR DECISÕES PÚBLICAS POR MEIO DA TÉCNICA NUDGE.

Luciana Cristina Souza, Karen Tobias França Ramos e Sônia Carolina Romão Viana Perdigão

Políticas públicas e o deVer de monitoramento: “LEVANdo os Direitos A SÉrio". .252 Ana Paula de Barcellos

Nudges E POLÍticas PÚblicas: uM MECANISMO DE COMBATE AO TRABALHO EM CONDIÇÃo ANÁLOGA À DE ESCRAVO .267

Amanda Carolina Souza Silva, Débhora Renata Nunes Rodrigues e Saul Duarte Tibaldi

REDUZINDO A TRIBUTAÇÃO COGNITIVA: LIÇÕES COMPORTAMENTAIS PARA A DIMINUIÇÃO DOS EFEITOS PSICOLÓGICOS ADVERSOS DA POBREZA.............................................................288 Leandro Novais e Silva, Luiz Felipe Drummond Teixeira, Gabriel Salgueiro Soares e Otávio Augusto Andrade Santos

Políticas PÚBLICAS EM SUICÍDIO: DO PATERNALISMO CLÁSSICO AO PATERNALISMO LIBERTÁRIO E NUDGING

Davi de Paiva Costa Tangerino, Gabriel Cabral e Henrique Olive

Nudges COMO POLÍticA PÚbliCA PARA AUMENTAR O ESCASSO NÚMERO DE DOADORES DE ÓRGÃos PARA TRANSPLANTE

Roberta Marina Cioatto e Adriana de Alencar Gomes Pinheiro

Os PROGRAMAS DE INTEGRIDADE PARA CONTRATAÇÃO COM A ADMINISTRAÇÃO PÚBLICA ESTADUAL: NUDGE OU OBRIGAÇÃo LEGAL? UM OLHAR SOBRE AS DUAS PERSPECTIVAS .386

Cíntia Muniz Rebouças de Alencar Araripe e Raquel Cavalcanti Ramos Machado

Paternalismo libertário e Proteção JURídica do AMbiente: POR QUe PROTEger o AMBIENTE TAMBÉM DEVE SER PROTEGER AS LIBERDADES?

Mariana Carvalho Victor Coelho e Patryck de Araujo Ayala

Políticas PÚblicas baseadas EM EVIdÊNCIAS COMPORTAMENTAIS: REFLEXões A PARTIR do Projeto de Lei 488/2017 do Senado

Pâmela de Rezende Côrtes, André Matos de Almeida Oliveira e Fabiano Teodoro de Rezende Lara

III. ECONOMIA COMPORTAMENTAL: VIESES COGNITIVOS E POLÍTICAS PÚBLICAS .455

ECONOMIA COMPORTAMENTAL E DIREITO: A RACIONALIDADE EM MUDANÇA Marcia Carla Pereira Ribeiro e Victor Hugo Domingues

VIESES COGNITIVOS E DESENHO DE POLÍTICAS PÚBLICAS 
A neurociênCia da moralidade na tomada de DeCisões Jurídicas Complexas e No DESENHO DE POLÍTICAS PÚBLICAS

Erik Navarro Wolkart

Desvio de CARÁter ou SIMPLESMENTE HUMANO? ECONOMIA COMPORTAMENTAL APLICADA AO COMPORTAMENTO DESONESTO

Diana Orghian, Gabriel Cabral, André Pinto e Alessandra Fontana

Políticas Públicas e a ConcretizaÇão de direitos sociais: TOMAdA DE DECisão, ARQUITETURA DE ESCOLHAS E EFETIVIDADE

Ana Elizabeth Neirão Reymão e Ricardo dos Santos Caçapietra

BEHAVIORAL ECONOMICS E DIREITO DO CONSUMIDOR: NOVAS PERSPECTIVAS PARA O ENFRENTAMENTO DO SUPERENDIVIDAMENTO .568

Samir Alves Daura

A EDUCAÇÃo FORMAL PARA O CONSUMO É GARANTIA PARA UMA PRESENÇA REFLETIDA DO CONSUMIDOR NO MERCADO? UMA ANÁLISE COM BASE NA BEHAVIORAL LAW AND ECONOMICS (ECONOMIA COMPORTAMENTAL) 600

Marcia Carla Pereira Ribeiro e Edson Mitsuo Tiujo

LIBET, DETERMINISMO E CONSUMO: AS INFLUÊNCIAS DO MARKETING E A RELEVÂNCIA DA DELIBERAÇÃo CONSCIENTE NA SUPERAÇÃo CONDICIONAL DE HÁBITOS DE CONSUMO PERIGOSOS616 Émilien Vilas Boas Reis e Leonardo Cordeiro de Gusmão

CiÊNCIA DO DIREITO TRIBUTÁRIO, ECONOMIA COMPORTAMENTAL E EXTRAFISCALIDADE. .640 Hugo de Brito Machado Segundo

IV. CoMportamento JUdiCiAL: INFLUÊNCIA DE FATORES EXTRAJURÍDicos .660

FATORES METAPROCESSUAIS E SUAS INFLUÊNCIAS PARA A FORMAÇÃo DA DECISÃo JUDICIAL .662 Rogério Roberto Gonçalves de Abreu, Lúcio Grassi de Gouveia e Virgínia Colares

“A VIDA COMO ELA É": COMPORTAMENTO ESTRATÉGICO NAS CORTES Patrícia Perrone Campos Mello

A COMPOSIÇÃo do ÓRGão COLEGIAdo E SEUS EFEITOS NA TOMADA DE DECISÃo .720 André Garcia Leão Reis Valadares

Das 11 ilhas ao centro do arquipélago: os superpoderes do Presidente do STF DURANTE O RECESSO JUDICIAL E FÉRIAS .741 José Mário Wanderley Gomes Neto e Flávia Danielle Santiago Lima 
RAZÃo, EMOÇÃo E DELIBERAÇÃO: AS ADEQUAÇÕES REgIMENTAIS do SUPERIOR TribUNAL DE JUSTIÇA PARA A FORMAÇÃo DE PRECEDENTES EFICAZES

Peter Panutto e Lana Olivi Chaim

Heurística de ancoragem e fiXaÇÃo de danos morais em JUizados especiais Cíveis no Rio DE JANEIRO: UMA NOVA ANÁLISE 778

Fernando Leal e Leandro Molhano Ribeiro

LA PROTECCIÓN DE LOS DERECHOS POLÍTICOS FRENTE A LAS FUNCIONES DISCIPLINARIAS DE LAS AUTORIDADES ADMINISTRATIVAS: SUBSIDIARIEDAD Y DEFERENCIA EN EL SISTEMA INTERAMERICANO DE DERECHOS HUMANOS Jorge Ernesto Roa Roa

V. A influênCia do gÊNERo no PROCESSO DECisório JUdiCial

Como os Juízes decidem os Casos de estupro? ANALISANDo SENTENÇAS SOb A PERSPECTIVA DE VIESES E ESTEREÓTIPOS DE GÊNERO 826 Gabriela Perissinotto de Almeida e Sérgio Nojiri

GÊNERO E COMPORTAMENTO JUDICIAL NO SUPREMO TRIBUNAL FEDERAL: OS MINISTROS CONFIAM MENOS EM RELATORAS MULHERES?

Juliana Cesario Alvim Gomes, Rafaela Nogueira e Diego Werneck Arguelhes

Hércules, Hermes e a Pequena Sereia: uma reflexão sobre estereótipos de gênero, SUBPRESENTAÇÃo DAS MULHERES NOS TRIBUNAIS E (I)LEGITIMIDADE DEMOCRÁTICA DO PODER JUDICIÁRIO. .878 Jane Reis Gonçalves Pereira e Renan Medeiros de Oliveira

Prisão Cautelar de gestantes: análise do Fundamento filosófico da decisão do Habeas CoRpus N. 143.641 912

Artur César Souza e Giovania Tatibana de Souza

VI. Neurodireito APlicado ao direito E Ao Processo PENAL....................................926

CÉREbros QUe PUNEM: UMA REVISÃo CRÍTICA DA NEURoCIÊNCIA DA PUNIÇÃo .....................928 Ricardo de Lins e Horta

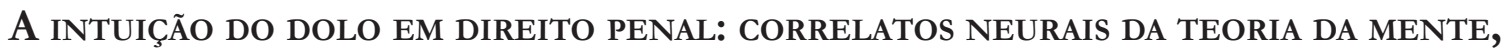
RACIOCÍNIO INDUTIVO E A GARANTIA DA CONVICÇÃO JUSTIFICADA. .946 Thiago Dias de Matos Diniz e Renato César Cardoso

As COMUNIDADES EPISTÊMICAS PENAIS E A PRODUÇÃo LEGISLATIVA EM MATÉRIA CRIMINAL..... 961 Stéphane Enguéléguélé 
DELINQUÊNCIA JUVENIL: RELAÇÕES ENTRE DESENVOLVIMENTO, FUNÇÕES EXECUTIVAS E COMPORTAMENTO SOCIAL NA ADOLESCÊNCIA .

André Vilela Komatsu, Rafaelle CS Costa e Marina Rezende Bazon

Límites TEMPORALES A LAS PENAS PRIVATIVAS DE LIBERTAD ATENDIENDO AL DESARROLLO PSICOSOCIAL.

Silvio Cuneo Nash

NEURolaw E AS PERSPECTIVAS PARA UMA ANÁLISE OBJETIVA DO COMPORTAMENTO SUGESTIONADO: REPERCUSSÃO DAS FALSAS MEMÓRIAS NA ESFERA PENAL

Mariana Dionísio de Andrade, Marina Andrade Cartaxo e Rafael Gonçalves Mota

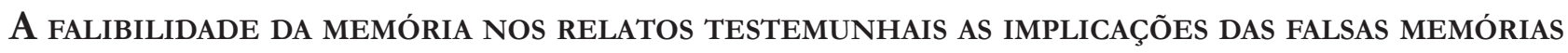
NO CONTEXTO DOS CRIMES CONTRA A DIGNIDADE SEXUAL

Caroline Navas Viana

A (IR)REPETIBILIDADE dA PROVA PENAL DEPENDENTE DA MEMÓRIA: UMA DisCUSSÃo COM BASE NA PSICOLOGIA DO TESTEMUNHO. 1058

William Weber Cecconello, Gustavo Noronha de Avila e Lilian Milnitsky Stein 


\title{
Economia comportamental e direito: a racionalidade em mudança*
}

\section{Behavioral economy and law: rationality under change}

\author{
Marcia Carla Pereira Ribeiro** \\ Victor Hugo Domingues***
}

\section{Resumo}

$\mathrm{O}$ artigo busca demonstrar a mudança de paradigma do conceito de racionalidade econômica a partir da Economia Comportamental e como a ocorrência desse fenômeno alterou a formulação de políticas públicas e o seu conjunto de proposições normativas. Para isso apresenta-se a trajetória histórica do pensamento econômico, que transitou de um conceito de racionalidade forte, para o qual o indivíduo tem preferências completas e estáveis, para um conceito de racionalidade fraca, no qual o indivíduo não apresenta condições de realizar as melhores escolhas, uma vez que está condicionado por vieses psicológicos que afetam suas preferências e, por via reflexa, sua condição de bem-estar social. Em seguida, com base nas descobertas da Teoria da Prospecção de Amos Tversky e Daniel Kahneman, demonstrou-se como as políticas públicas foram influenciadas pelos mecanismos de Economia Comportamental, mediante aplicação de um novo desenho de incentivos, especialmente de natureza normativa. Concluiu-se que que a mudança da concepção do conceito de racionalidade foi determinante para a adoção de novos formatos de políticas públicas. Da mesma forma, foi possível concluir que a Economia Comportamental, quando aplicada às políticas públicas, amplia a interferência do Estado regulador em ambientes antes reservados à autonomia privada. Finalmente, propõe-se a ampliação de um debate que ainda não foi realizado no Brasil, sobre os limites e perspectivas de aplicação de ferramentas da Economia Comportamental às políticas públicas.

Palavras-chave: Racionalidade. Economia Comportamental. Políticas Públicas.

* Recebido em 18/04/2018 Aprovado em 21/05/2018

** Mestre e Doutora em Direito. Professora titular do Programa de Pós Graduação em Direito da PUCPR. Professora Associada da graduação e do Programa de Pós Graduação em Direito da UFPR. Advogada. Parecerista e Árbitra. E-mail: marcia.ribeiro@pucpr.br

*** Mestre em Direito pela PUCPR. Doutorando na PUCPR. Secretário Municipal de Balneário Camboriú, SC. E-mail: victorhugodom@gmail.com

\section{Abstract}

The purpose of this article is to present the paradigm shift that took place in economic rationality through Behavioral Economics; how this has provided a new mindset in public policies development and its legal system. At first, the paper sets forth the evolvement of economic thinking from the concept of strong to weak rationality. The first concept took the individual for capable of full and stable preferences, whereas the second one (weak rationality) stated that individuals weren't able to make the best choices, be- 
cause they were conditioned by psychological biases that affected their preferences and social well-being. Following, the article will depict the Prospecting Theory of Amos Tversky and Daniel Kahneman, through which it came through that public policies were influenced by Behavioral Economics mechanisms. The authors' work was relevant in stablishing new incentive design, especially normative ones. The concluding part implies that this transition in rationality concept resulted from the adoption of new formats of Public Policies. The conclusion went further, suggesting that Behavioral Economics, when applied to Public Policies, causes regulatory State meddling to increase, particularly in private environments. The outcome is to engender a debate quite not held in Brazil yet, regarding limits and perspectives of the Behavioral Economy as the main element in public policies development.

Keywords: Rationality. Behavioral Economics. Public Policies.

\section{INTRODUÇÃo}

O artigo buscou percorrer o trajeto teórico científico da Teoria da Racionalidade Econômica e compreender como a Economia Comportamental alterou, significativamente, as bases analíticas sobre a natureza dos processos de decisão dos indivíduos em sociedade. Por sua vez, essa modificação de paradigmas foi determinante para incluir nas ferramentas de políticas públicas mecanismos de influência, delimitação e orientaçãoão das escolhas. A partir dos questionamentos acerca da racionalidade do agente econômico, a Economia Comportamental invalidou uma série de pressupostos que vinham sendo reiterados pela economia ortodoxa. O principal deles é a suposição de que as pessoas sempre escolhem o melhor para si mesmas e que sempre maximizarão suas preferências de acordo com um critério próprio de utilidade escalonada. Conforme ficará demonstrado adiante, tais pressupostos deixaram de ser cientificamente válidos, já que os indivíduos podem falhar durante o processo decisional, seja por razões externas ou por razões de natureza psicológica.

Muitas vezes, as escolhas realizadas sob a influência de processos mentais obscuros conduzem os indivíduos a tomar decisões deletérias. Os exemplos adiante mencionados poderão evidenciar os comportamentos vulneráveis, tomados por impulso de problemas de cognição, os quais formam um padrão de repetição contrária ao interesse dos próprios agentes. Quando somadas, essas armadilhas mentais provocadas por vieses e heurísticas da condição humana, reduzem, significativamente, a condição de bem-estar social.

O artigo traz à reflexão a constatação de que se, por um lado, as pessoas fazem suas escolhas de forma equivocada, causando a diminuição da sua própria qualidade de vida, compete ao Estado de Bem-Estar social providenciar meios para que as pessoas façam melhores escolhas. Justifica-se, dessa forma, a intervenção do planejador central como agente influenciador do processo de formação das preferências. Logo, todo um arcabouço de técnicas normativas é criado para influenciar o comportamento das pessoas. É o que se busca demonstrar na terceira parte deste artigo. Ao final, destacou-se possíveis problemas acerca da violação da autonomia pessoa, da livre e consentida escolha dentro da lei e o autogoverno das ações individuais.

Por todos esses desafios à razão, as dúvidas quanto ao alcance da Economia Comportamental estão hoje na pauta das discussões acadêmicas e políticas dos países de elevado grau de desenvolvimento social e econômico. Por outro lado, os valores jurídicos da autonomia, do livre consentimento e da liberdade de ação levantam novos questionamentos sobre os limites da atuação dos programas governamentais que, em nome do bem-estar social, fazem uso do behaviorismo como instrumento de efetivação de políticas públicas. 


\section{A ECONOMIA COMPORTAMENTAL COMO PONTO DE PARTIDA}

A história da regulação estatal não é recente. Toda organização política estipula, com maior ou menor interferência, as regras de comportamentos tolerados pela coletividade. Apenas recentemente, instituições governamentais foram persuadidas a utilizar o ferramental da Economia Comportamental como um instrumento para atingir os objetivos sociais do bem-estar social ${ }^{1}$. Porém, há uma diferença significativa entre coagir e influenciar, exigir e manipular. Esses exercícios de conformação dos comportamentos são mais controversos quando, revestidos da força normativa do ente estatal, influem no domínio privado das escolhas econômicas e sociais. Os seus mecanismos de persuasão, como mencionado no título do último livro de Cass Sustein ${ }^{2}$, levantam questionamentos de ordem ética e política, a respeito de onde e como a aplicação dessa influência estatal está de acordo com outros princípios informadores da legislação. Identificar os caminhos pelos quais esse debate tomou forma, especialmente por meio da análise histórica do pensamento econômico e social, facilita o entendimento sobre o plano geral em que se situa a teoria econômica behaviorista e sua aplicação nas políticas públicas dos mais variados setores.

\subsection{O Behaviorismo: Passado, Presente e Futuro}

A Economia Comportamental, também conhecida como Behaviorismo, surgiu em meados da década de 70 do Século passado, como uma resposta sólida e sistematizada ao pressuposto dogmático da racionalidade econômica ${ }^{3}$, pilar teórico da Escola Neoclássica da Economia.

A ciência econômica se apresentou, nas últimas décadas do Século XX, como instrumento político hábil para desvendar o enigma da alocação da riqueza, sinalizando o destino dos recursos finitos com vista à eficiência econômica. No caso, a Teoria da Racionalidade ${ }^{4}$ das Escolhas, pilar fundamental da política econômica do século passado, pressupõe que as opções humanas seriam sempre estáveis, constantes e transitivas, de forma a permitir que as previsões econômicas pudessem gozar de alto grau de confiança e previsibilidade.

A História do Pensamento Econômico está repleta de vertentes e teorias que seguiram por diferentes caminhos para solucionar o problema da alocação da riqueza em uma sociedade de bens escassos ${ }^{5}$. Partindo-se do interesse de Alfred Marshall em desvendar as causas da pobreza, até os recentes escritos de Amartya Sen ${ }^{6}$, a defender a plena liberdade individual de escolha como sinônimo de desenvolvimento econômico, nota-se que a excessiva matematização de modelos racionais não foi uma construção teórica unânime e imune às críticas. Uma análise pormenorizada da evolução científica da Economia, e a latente controvérsia sobre seu estatuto epistemológico sugere a existência de forte relação entre as formas de atuação do Estado no cenário político econômico, e o programa jurídico-político que lhe dá fundamento ${ }^{7}$. A construção das teorias

1 O Governo Britânico faz parte da comissão especialmente dedicada para elaborar políticas públicas comportamentais, denominado The Behavioral Insights Team (BIT). É a primeira iniciativa governamental de criação de um bureau para propor políticas públicos de baixo custo e de fácil adaptação ao público em geral. Um dos seus objetivos é propiciar que "as pessoas façam melhor escolhas para elas mesmas". Para conferir a recente discussão sobre Políticas Públicas e Economia Comportamental na Colômbia cfr. MONROY, Daniel. Nudges y Decisiones inconscientes: sesgo de statu quo y políticas públicas em Colombia. Revista desafios, Bogotá, v. 29, n. 1, p. 211-247, dic. 2016. Sobre o impacto do Direito e da Economia Comportamental ao redor do globo cfr. WHITEHEAD, Mark et al. Nudging all over the World: assessing the global impact of the behavioural sciences on public policy. Economic \& Social Research Council, Aberystwyth, p. 1-38, sep. 2014.

2 SUSTEIN, Cass. The ethics of influence. New York: Cambridge University Press, 2017.

3 RIBEIRO, Márcia Carla Pereira. Racionalidade limitada. In: RIBEIRO, Márcia Carla Pereira; KLEIN, Vinicius (Coord.) O que é análise econômica do direito: uma introdução. 2. ed. Belo Horizonte: Fórum, 2016. p. 64-65.

4 PRADO, Eleutério F. S. A ortodoxia neoclássica. Estudo Avançados, São Paulo, v. 15, n. 41, p. 9-20, jan./abr. 2001.

5 MURAMATSU, R. The death and resurrection of economics with psychology: remarks from a methodological standpoint. Revista de Economia Política, São Paulo, v. 29, p. 62-81, 2009.

6 SEN, A. Desenvolvimento como liberdade. São Paulo: Cia. das Letras, 2000.

7 Não existem programas políticos completamente neutros do ponto de vista ideológico. Mesmo as cartas constitucionais elaboradas após o advento do Estado moderno carregam valores políticos ideológicos capaz de classificar os Estados em maior ou menor 
e modelos econômicos parece ter sido fortemente influenciada pelas escolas científicas contemporâneas e pelas concepções vigentes acerca do que era ciência econômica, do que deveria ser a ciência econômica e de como deveria ser a apresentação formal de um conhecimento propriamente científico a dar sustentação aos programas políticos com fundamento em pressupostos econômicos.

Durante o Século XX, as interferências recíprocas entre a Economia e a Matemática — ora tida como ferramenta, ora declarada como objetivo - materializaram esse conflito. Da mesma forma, se deu a relação entre Psicologia e a Economia ${ }^{8}$. Em muitos momentos, as teorias econômicas deixaram de apresentar unanimidade acerca do que seria o próprio objeto de estudo da Economia. Alguns defensores do mainstream ${ }^{9}$ econômico afirmaram que a falta de concordância entre economistas provém, apenas, da dificuldade em reduzir realidades complexas em modelos teóricos com pouca fidedignidade. Os críticos sugerem que esse movimento em direção à matematização da Economia não contribuiu para a confirmação dos pressupostos da racionalidade (preferências estáveis e contínuas), visto que as previsões econômicas demonstraram pouca capacidade normativa, gerando uma espécie de vácuo epistemológico. Os trabalhos de economistas como Herbert Simon ${ }^{10}$, Shira Lewin ${ }^{11}$ e Robert Sugden ${ }^{12}$ assinalam que houve uma bifurcação na teorização econômica a partir da década de 50 do Século passado, uma guinada da Economia para a excessiva matematização dos modelos e predições econômicas ${ }^{13},{ }^{14}$.

As construções dos primeiros teóricos refletiam essa busca pelo entendimento acerca das causas do comportamento econômico. Suas análises se debruçavam sobre os fatores que propulsionavam a ação, e por isso eram extremamente subjetivas (ênfase para o desenvolvimento da Teoria da Utilidade ${ }^{15}$ ). Para teorizar sobre a causa geradora da ação econômica, era necessário considerar, também, as motivações subjetivas, campo de estudos afeto à psicologia humana. Num segundo momento, os teóricos neoclássicos deixaram ao largo todas as variáveis que pudessem denotar razões de natureza subjetiva ${ }^{16}$, dando ênfase à teoria hipotética em prejuízo da experiência empírica. A Teoria da Utilidade — principal construção dos Primeiros

grau de adesão à liberdade e à autonomia individual, por exemplo. Cf. SOWELL, Thomas. Conflito de visões: origens ideológicas das lutas políticas. São Paulo: É Realizações, 2011.

8 Sobre a discussão acerca da inconstante relação da Economia com a Psicologia cfr. LEWIN, Shira B. Economics and psychology: lessons for our own day from the early twentieth century. Journal of Economic Literature, v. 34, n. 3, p. 1293-1323, set. 1996, e MURAMATSU, Roberta; FONSECA, Patrícia. Um enigma do comportamento do consumidor no Brasil: análise comportamental do consumo procrastinado em um cenário inflacionário. In: ENCONTRO DA ANPAD, 32., Rio de Janeiro, 2008.

Para uma leitura sobre o desencontro de percepções acerca do papel da Matemática na Economia, consultar as distintas compreensões de MARSHAL, Alfred. Principles of economics. 8. ed. Londres: McMillian, 1920; e SAMUELSON, Paul. Fundamentos da análise econômica. São Paulo: Nova Cultural, 1998; o primeiro defende o papel acessório e secundário da Matemática na Economia, enquanto o último a apresenta como central para a construção e evolução da teorização econômica.

9 A corrente teórica predominante na Ciência Econômica é regularmente citada como mainstream, e alguns autores e economistas usam a palavra como um sinônimo para Economia Neoclássica, que seria uma das correntes existentes em teorização econômica e sem dúvida a mais disseminada. No entanto faz-se necessária aqui uma ressalva, visto que o termo é utilizado de forma equivocada e incompleta. Economia Neoclássica como vulgarmente se apresenta é mais precisamente a Economia Neoclássica do pós-guerra. Cf. MANDLER, Michael. Dilemmas in economic theory: persisting foundational problems in microeconomics. New York: Oxford, 1999, profundamente enraizada na matematização, e em modelos abstratos e gerais, incrustados na noção de racionalidade. As obras de grande parte do que seriam os "primeiros neoclássicos" (ou Neoclássicos da primeira geração), diferem pontualmente desse segundo grupo em termos de inspiração, metodologia, objeto de estudo e objetivos, merecendo portanto tal distinção.

10 SIMON, H. Alternative visions of rationality. In: ARKES, H.; HAMMONDS, K. (Coord.) Judgement and decision making. Cambridge: Cambridge University Press, 1986.

11 LEWIN, Shira B. Economics and psychology: lessons for our own day from the early twentieth century. Journal of Economic Literature, v. 34, n. 3, p. 1293-1323, sep. 1996.

12 BRUNI, Luigino; SUNGDEN, Robert. The road not taken: how psychology was removed from economics, and how it might be brought back. The Economic Journal, Rio de Janeiro, v. 117, n. 516, p.146-173, 2007.

13 MURAMATSU, R. The Death and resurrection of economics with psychology: remarks from a methodological standpoint. Revista de Economia Política, São Paulo, v. 29, p. 62-81, jan./mar. 2009.

14 MURAMATSU, R. The death and resurrection of economics with psychology: remarks from a methodological standpoint. Revista de Economia Política, São Paulo, v. 29, p. 62-81, jan./mar. 2009.

15 Sobre a Teoria da Utilidade cf. JEVONS, Willian S. The theory of political economy. Londres: McMillian, 1888.

16 LEWIN, Shira B. Economics and psychology: lessons for our own day from the early twentieth century. Journal of Economic Literature, v. 34, n. 3, p. 1293-1323, set. 1996. 
Neoclássicos - postulava que as pessoas escolhem buscando maximizar o prazer e minimizar a dor. Numa segunda fase da Teoria Econômica Neoclássica, a inovação teórica consistia no conceito de "marginalidade", em que o consumo de bens ou produtos cessa quando a utilidade marginal (ou utilidade advinda com a compra de mais uma unidade) se iguala ao custo de obtê-la.

A "Revolução Marginalista", tendo como centro o desenvolvimento da supracitada Teoria da Utilidade, compreendeu que o valor de um bem é definido não somente pelo trabalho (custo), mas também pela utilidade marginal que o indivíduo espera obter das escolhas realizadas. A "Revolução Marginalista" traz as primeiras representações de curvas de oferta (lado dos custos) e curvas de demanda (lado da utilidade) para a determinação de preços de mercado. No começo do Século XX, a Teoria da Utilidade enfrentava considerável crise epistemológica ${ }^{17}$. Não era possível matematizar as motivações de cunho psicológico dos agentes. Os modelos racionais baseados na estabilidade e previsibilidade das escolhas humanas não explicavam os desvios no padrão das escolhas esperadas. Enquanto a Economia se mantinha com suas suposições de racionalidade e escolha consciente, a Psicologia, Sociologia e outras Ciências Sociais caminhavam para as conclusões de seus experimentos que muitas vezes mostravam que as escolhas dos agentes econômicos podem se dar num ambiente desprovido de lógica racional ${ }^{18}$. A Economia se viu assim frente a um dilema. Matematizar era contribuir para o avanço científico da área, no entanto não era possível traduzir a inconstância psicológica humana para o rigor e estabilidade de funções matemáticas. Os conceitos psicológicos contidos nas teorias econômicas (p. ex. utilidade e prazer) não eram passíveis de matematização ${ }^{19}$.

Esse foi o estopim de um movimento que levou a Teoria Econômica a se afastar dos preceitos psicológicos em relação à formulação das análises normativas e positivas. Abandonava, assim, não somente a discussão acerca dos valores morais de que fazia uso, mas toda e qualquer fundamentação psicológica. A Matemática tornou-se, a partir de então, um objetivo da ciência Econômica, e não mais uma ferramenta. Desse modo, toda a inspiração psicológica que existia nas teorias até o começo do Século XX foi ignorada pela ciência econômica. Durante o Século XX, as considerações de Adam Smith sobre como a simpatia, enquanto guia das atitudes econômicas, foi relegada a pesquisas de natureza unicamente filosóficas. Ficaram para trás, também, as considerações de Nassau Senior e William Stanley Jevons sobre aspectos emocionais da postergação do consumo presente, assim como as considerações morais, altruístas e culturais no hábito de poupança feitas pelo economista Irwing Fisher ${ }^{20}$.

Não era possível, dentro do novo paradigma científico pretendido pela Economia, discorrer sobre emoção, simpatia, altruísmo, moralidade ou cultura. Nenhuma dessas variáveis compunha as fórmulas quantitativas da Economia do Século XX. Nesse passo, a Teoria da Racionalidade Econômica contribuiu para o argumento tautológico da abordagem das preferências reveladas. De acordo com a Teoria das Preferências Reveladas, um agente revelava suas preferências no momento da escolha, e essa conclusão de que os agentes "escolhem o que preferem" era derivada do argumento circular de que os agentes racionais "preferem o que escolhem". Essa simplificação retórica fundamentou o afastamento dos contributos da Psicologia na ciência econômica, uma vez que não era mais necessário investigar as motivações humanas subjacentes às escolhas, como faziam os primeiros economistas clássicos. A partir de então, as motivações do agente econômico não seriam mais consideradas para calcular os desdobramentos da formação da vontade e do exercício da escolha ${ }^{21}$.

17 A crise epistemológica da Teoria da Utilidade se refere a modificação de um dos seus pressupostos elementares, o de que os comportamentos dos agentes econômicos são determinados unicamente pelas suas preferências individuais. Cfr. SANTOS, Cordeiro dos. The social epistemology of experimental economics. New York: Routledge, 2009. p. 162.

18 MURAMATSU, R. The death and resurrection of economics with psychology: remarks from a methodological standpoint. Revista de Economia Política, São Paulo, v. 29, p. 62-81, jan./mar. 2009.

19 MURAMATSU, Roberta; FONSECA, Patrícia. Economia e psicologia na explicação da escolha intertemporal. Revista de Economia Macken₹ie, São Paulo, v. 6, n. 6, p. 87-112, 2008.

20 FISHER, Irwing. The theory of interest. New York: Macmillan, 1930.

21 MURAMATSU, R. The death and resurrection of economics with psychology: remarks from a methodological standpoint. Revista de Economia Política, São Paulo, v. 29, p. 62-81, jan./mar. 2009. 
Desse modo, o princípio da racionalidade não somente permitiu, de um lado, o afastamento da Psicologia por meio da Teoria das Preferências Reveladas, como impulsionou a matematização da Economia. Assim, a Economia postulava como suposição auxiliar que "agentes racionais são consistentes". Ser consistente significa que uma pessoa escolhe, entre duas alternativas, a mesma opção tanto hoje quanto em qualquer outro momento do tempo ${ }^{22}$. Dizer isso é negar a existência de instâncias de arrependimento, e a possibilidade de ocorrência de aprendizado e socialização, instâncias do comportamento que são fundamentais para o estudo da norma jurídica, por exemplo.

A superação do paradigma da racionalidade absoluta do agente econômico ocorreu somente no início da década de 70, com o conjunto de estudos atribuídos a Amos Tversky e Daniel Kahneman, pesquisadores que ganharam notoriedade no meio acadêmico por suas pesquisas no âmbito da economia e psicologia comportamental. A Teoria da Perspecção fundou um novo ramo da economia, então nomeado behavioral economics. A Economia Comportamental ganhou notoriedade por contestar um dos mais preciosos fundamentos do mainstream acadêmico: a racionalidade do homus economicus. Segundo Taversky e Kahneman ${ }^{23}$, as motivações racionais e as motivações emocionais têm papel preponderante no processo de escolhas econômicas, e atuariam de forma a moldar a percepção dos incentivos econômicos, tanto positivamente quanto negativamente. A quantidade e a procura de determinados bens são influenciadas por uma série de variáveis que refogem à simples análise dos preços, ou mesmo à disponibilidade da renda, muito embora se reconheça o impacto fundamental que esses dados objetivos apresentam para a formação da curva da oferta e demanda. É nesse ponto que a Economia Comportamental exerce um papel central ao criticar o pressuposto da racionalidade dos agentes econômicos ${ }^{24}$.

Para os comportamentalistas, há muito mais que dados objetivos a influir entre as preferências declaradas e as escolhas efetivamente realizadas; e, em relação a isso, a identificação dos desvios cognitivos e dos equívocos decorrentes de processos mentais obscuros pode explicar, com mais precisão, as razões pelas quais os agentes econômicos não se comportam como previsto pelos modelos economáticos. Amos Tversky e Daniel Kahneman foram os cientistas mais notáveis nesse campo do conhecimento, sendo, inclusive, agraciados com o Nobel de Economia em 2002. A Prospect Theory - elaborada pelos dos dois cientistas após inúmeros experimentos — descobriu que as decisões nem sempre são ótimas, e que estão sujeitas a uma série de distorções do julgamento (vieses) e atalhos mentais muitas vezes simplórios, que, diante de problemas complexos, apresentam respostas singelas e automatizadas, entretanto, nem sempre corretas (heurísticas) ${ }^{25}$.

Tversky e Kahneman descobriram que, diante de um quadro de incertezas, ou de informações incompletas, as pessoas apresentam uma série de reações que não podem ser consideradas racionais, conforme intuiam os economistas neoclássicos. Ao contrário, as pessoas são limitadamente racionais, uma vez que suas efetivas escolhas dependem, dentre outras coisas, da forma como as questões são apresentadas (framing) e de sua disposição para assumir riscos (risk aversion), especialmente num ambiente de incertezas.

Por tais motivos, as escolhas não são racionais, mas sim limitadas a uma série de fatores que bloqueiam a opção ótima. A disposição de manter o status quo (inertia), o sentimento de apego e posse (endowment effect), o equívoco no julgamento sobre os efeitos ao longo do tempo (byperbolic discount), a insistência em escolhas ruins (sunk cost) etc. são manifestações neurocognitivas que podem ser estimuladas ou evitadas de acordo com os incentivos aos quais os agentes econômicos são expostos (arquitetura dos incentivos).

Por essa razão, a Economia Comportamental pode exercer um papel relevante na elaboração de políticas

22 MURAMATSU, R. The death and resurrection of economics with psychology: remarks from a methodological standpoint. Revista de Economia Política, São Paulo, v. 29, p. 62-81, jan./mar. 2009.

23 TVERSKY, Amos; KAHNEMAN, Daniel. Judgement under uncertainty: heuristics and biases. Science, v. 185, n. 4157, p. $1124-$ 1131, sep. 1974.

24 SHAFIR, Eldar. The behavioral foundations of public policy. Princeton: Princeton, 2012. p. 32.

25 MURAMATSU, R. The death and resurrection of economics with psychology: remarks from a methodological standpoint. Revista de Economia Política, São Paulo, v. 29, p. 62-81, jan./mar. 2009. 
públicas ${ }^{26}$ que buscam evitar a tomada de decisões trágicas no cenário econômico. $\mathrm{O}$ behaviorismo não pressupõe que as pessoas sejam sensatas e plenamente consciente de suas escolhas (racionalidade forte) ${ }^{27}$, ao contrário. Seus pressupostos consistem em sugerir que os agentes econômicos são irracionais, e a consequência de suas escolhas podem ser desatrosas ${ }^{28}$. Um conjunto de decisões equivocadas pode conduzir o destino de uma sociedade a um elevado risco de vulnerabilidade social. Uma perspectiva mais realista do comportamento dos agentes econômicos informa, de maneira mais fidedigna, os agentes políticos, de maneira a evitar, informar e corrigir comportamentos indesejados, ou mesmo viciados pela falsa presunção de racionalidade.

$\mathrm{Na}$ verdade, o pano de fundo do debate sobre a Teoria da Racionalidade Econômica e suas diferentes correntes traz, mesmo que de forma implícita, os programas políticos e econômicos que orbitam em torno da questão da intervenção do Estado no domínio econômico ${ }^{29}$. A racionalidade forte, como sustentavam os economistas neoclássicos, foi um importante fundamento de defesa em favor do lessaiz faire e do livre mercado. Como as escolhas dos agentes econômicos eram estáveis, o ajuste econômico da curva da oferta e demanda se ajustaria, automaticamente, mediante a natureza prórpria do equilíbrio entre as forças da produção e do consumo. A teoria se ajustava, perfeitamente, à ideia da mão invisível de Adam Smith, em que a autoregulação e os interesses recíprocos e voluntários eram suficientes para perfeito funcionamento das trocas que caracterizam o livre mercado, por exemplo.

De outro lado, supor que as escolhas econômicas não são estáveis, ou melhor, supor que as necessidades econômicas estão e são recortadas por elementos de natureza psicológica e comportamental ${ }^{30}$ modifica, completamente, o paradigma da ciência econômica, num primeiro momento. Num segundo momento, justificaria a intervenção estatal no domínio econômico para conduzir os comportamentos individuais a um nível socialmente desejado. Isso porque, invariavelmente, todo programa jurídico-político concede ao Estado importante papel em relação à promoção da Economia e do Bem-estar geral da sociedade ${ }^{31}$.

\section{O BEHAVIORISMO E A QUESTÃO SOCIAL}

A complexidade do comportamento humano e, principalmente, seus reflexos nos diversos segmentos sociais exigem novas abordagens políticas para tratar dos riscos e efeitos sociais de escolhas trágicas. As políticas públicas levadas adiante pelo Estado de bem-estar social devem buscar a mais verossímil aproximação do que efetivamente busca modificar ou estimular incentivos de natureza neuro-comportamental. Muitas vezes, pequenos ajustes de natureza legislativa podem transformar a forma como as pessoas reagem aos incentivos.

Um dos exemplos mais conhecidos sobre incentivos em políticas públicas foi testado com base no viés da "opção padrão" (option default) e no "enquadramento noticioso" (framing) em relação ao problema da es-

26 BARON, Jonathan. Biases in the quantitative measurement of values for public decisions. Psychological Bulletin, Filadélfia, n. 122, p. 72-88, 1997.

27 Williamson defende a existência de três tipos de racionalidade: forte, semiforte ou limitada e fraca. Assim, a racionalidade atribuída à teoria econômica neoclássica é classificada como racionalidade forte, que supõe o pleno conhecimento de todos os custos de transação pelo agente econômico. Cf. WILLIAMSON, O. E. The economic institutions of capitalism. New York: Free Press, 1985. 28 ARIELY, Dan. Positivamente irracional. Rio de Janeiro: Elsevier, 2010. p. 5.

29 Existem vários instrumentos constitucionais de intervenção no domínio econômico, todavia, sem qualquer menção aos mecanismos da Economia Comportamental. Para verificar uma análise de todas essas formas de intervenção permitidas no sistema constitucional cfr. NEVES, Antônio Francisco Frota; SANTANA, Hector Valverde. A intervenção direta e indireta na atividade econômica em face da ordem jurídica brasileira. Revista Brasileira de Políticas Públicas, Brasília, v. 7, n. 2, p. 332-348, ago. 2017.

30 LOHRENZ, Terry; MONTAGUE, P. Read. Neuroeconomics: what neuroscience can learn from economics. In: LEWIS, Alan. (Org.). The Cambridge handbook of psychology and economic behaviour. Cambridge: Cambridge University Press, 2008. p. 457.

31 BARON, Jonathan. Biases in the quantitative measurement of values for public decisions. Psychological Bulletin, Filadélfia, n. 122, p. 72-88, 1997. 
cassez de doação de órgãos ${ }^{32}$. Países com consentimento presumido sobre a doação tendem a colher resultados mais satisfatórios para a política pública de doação. Por excessiva manutenção do estado inercial, eventuais doadores de órgãos nunca efetivariam a doação por não terem uma postura ativa acerca da afirmação expressa da intenção de doar. Logo, optam pela opção padrão, ou seja, não se manifestam e não efetivam a doação. Com simples ajustes na política de doação de órgãos, alterando o enquadramento noticioso (framing) do programa de doação, de forma a tornar todas as pessoas doadoras presumidas (opt-out), o número das doações aumentou significativamente. Logo, a opção ativa (opt-in), que gera algum tipo de ação positiva do agente, passou a ser obrigação das pessoas que, efetivamente, não querem doar seus órgãos, devendo fazer manifestação expressa nesse sentido ${ }^{33}$.

Portanto, a integração entre o Direito, Economia Comportamental e Políticas Públicas pode ser justificada pela busca de métodos mais eficazes para evitar tragédias sociais provocadas pelo "espírito animal" dos agentes econômicos ${ }^{34}$. Sabe-se que um dos objetivos do Estado de Bem-estar Social contempla o papel do planejador central como ente regulador, por isso, a função do Estado tem relação direta com o comportamento dos agentes econômicos no ambiente social. Agir de acordo com os incentivos gerados pelo Poder Público revela um processo pelo qual uma organização ou indivíduo busca maximizar a função utilidade pelo ajustamento deliberado e consciente dos meios e fins ${ }^{35}$. Conforme já mencionado, para os behavioristas, empresas e pessoas não agem sempre conscientemente. Aliás, as escolhas sociais são conduzidas por vieses que levam a uma decisão não ótima ${ }^{36}$.

Condutas anticompetitivas provocadas por vieses de seleção, comportamento de manada em mercados de ativos, utilização irracional de bens comuns ${ }^{37}$ — levando à escassez de recursos ambientais —, são apenas alguns exemplos em que o Estado Regulador pode ser chamado a evitar conflitos decorrentes de comportamentos predatórios. A finalidade do Estado Regulador buscará os melhores incentivos comportamentais para evitar que os agentes econômicos sejam vítimas de suas próprias escolhas. Isso não seria possível sem antes superar o paradigma da racionalidade do agente econômico.

Nesse sentido, e mediante experimentos empíricos, a Teoria Econômica do Comportamento vem se destacando ao traduzir, cientificamente, os impulsos inconscientes das pessoas. A forma como as pessoas se prostram diante dos incentivos, e seus influxos recíprocos no seio do sistema legal, tornaram a Bebavioural Law and Economics uma área de estudos de alta relevância ${ }^{38}$. Por tal razão, o aspecto paternalista da ação governamental, segundo os behavioristas, levará o agente econômico a tomar decisões mais eficientes, com maior disponibilidade de informações, e menos suscetíveis às armadilhas mentais influenciadas por vieses e heurísticas.

A arquitetura de incentivos, utilizada como componente do sistema de regras jurídicas, se revelou uma alternativa indispensável para adequar as propostas políticas no campo social ${ }^{39}$. Por via dessa nova proposta

32 DAVIDAI, Shai; GILOVICH, Thomas; ROSS, Lee D. The meaning of default options for potential organ donors. Proceedings of the National Academy of Sciences, v. 109, n. 38, p. 15201-15205, sep. 2012.

33 DAVIDAI, Shai; GILOVICH, Thomas; ROSS, Lee D. The meaning of default options for potential organ donors. Proceedings of the National Academy of Sciences, v. 109, n. 38, p. 15201-15205, sep. 2012.

34 A expressão "espírito animal” é comumente atribuída à John Maynard Keynes, que para descrever as emoções que influenciam o comportamento humano. Cf. AKERLOFF, George; SHILLER, Robert. O espírito animal. Rio de Janeiro: Elsevier, 2009.

35 RIBEIRO, Márcia Carla Pereira. Racionalidade limitada. In: RIBEIRO, Márcia Carla Pereira; KLEIN, Vinicius (Coord.). O que é análise econômica do direito: uma introdução. 2. ed. Belo Horizonte: Fórum, 2016. p. 68.

36 Uma decisão não ótima aqui mencionada tem seu conceito extraído da Análise Econômica do Direito, no caso uma decisão de impacto jurídico que não obtém os máximos benefícios que poderiam advir se os recursos fossem empregados de maneira mais eficiente para a mesma situação.

37 CÁRDENAS, Juan Camilo. Groups, commons and regulations: experiments with villagers and students in Colombia. In: AGARWAL, Bina; VERCELLI, Alessandro (Eds.). Psychology, rationality and economic behavior. New York: Palgrave MacMillan, 2005. p. 241.

38 ARAÚJO, Fernando. Análise econômica do direito: programa e guia de estudo. Lisboa: Almedina, 2008. p. 37.

39 Dentre os behavioristas um argumento que é comumente utilizado para defender a formatação de programas jurídico-políticos mediante uso de incentivos comportamentais remonta à justificativa de John Stuart Mill, em defesa da liberdade e do princípio do 
metodológica de engenharia social, concede-se ao indivíduo maior capacidade de escolha. O indivíduo poderá decidir mais claramente entre as possibilidades que se lhe apresentam, sobretudo quando identificadas as limitações cognitivas às quais está submetido. Tal "clareamento" das escolhas serve, sobretudo, para descobrir as causas que enviesam as escolhas dos agentes ${ }^{40}$. São vastos os exemplos utilizados para sustentar a aplicação do behaviorismo em programas políticos ligados à promoção do Estado de Bem-estar social. Veja-se, por exemplo, as opções que envolvem questões como poupança e aposentadoria. Nesses casos específicos, os indivíduos apresentam severas dificuldades com o planejamento — e suas projeções — ao longo do tempo. A Teoria da Escolha Racional, baseada fundamentalmente no predicado estrito do autointeresse dos agentes econômicos, prevê que, em todas as ocasiões, as escolhas recairão sobre a hipótese da maximização dos benefícios próprios. No entanto, a Teoria Comportamentalista vem desmentindo tal característica atribuída ao indivíduo ${ }^{41}$. Por influência de uma perspectiva míope em relação ao futuro (viés de miopia), os indivíduos são dissuadidos de poupar para a senescência. Entretanto, quando atingem o momento da aposentadoria, o rendimento previdenciário é insuficiente para manter o mesmo nível de vida que gozavam quando em plena atividade econômica, o que leva muitos idosos a prorrogar o retiramento programado pelo governo.

Por muito tempo, os economistas ortodoxos permaneceram reticentes em acolher razões de natureza psicológica em políticas públicas. Todavia, a Economia Comportamental demonstra que existe um campo de atuação para influenciar (nudging) o comportamento dos agentes limitadamente racionais ${ }^{42}{ }^{43}$.

Ao permitir que os agentes econômicos tomem a melhor decisão num contexto de incertezas, o behaviorismo parte do pressuposto de que as pessoas, quando bem informadas, são incialmente dispostas a contribuir para o bem público e individual ${ }^{44}$, ou seja, os agentes são naturalmente altruístas, e esperam contribuições recíprocas de outras pessoas. A análise econômica comportamental, como menciona Cristhine Jolls $s^{45}$, quando atende um programa político desejado pelo Estado (ex: redução do uso de drogas, utilização de equipamentos de proteção individual no ambiente de trabalho, redução da obesidade mórbida etc.), deve fazer uso dos instrumentos de incentivos para atingir o comportamento que imagina ser adequado ${ }^{46}$. A análise econômica comportamental, unida ao Direito Público, visa diminuir a assimetria de informações para que o indivíduo tome a decisão de forma menos enviesada, cujo resultado amplia a rede de benefícios que, de outra forma, não estariam disponíveis ao indivíduo em condições normais, sem apresentar qualquer externalidade negativa. ${ }^{47}$

utilitarismo. Segundo Mill, as mais usuais formas de coerção vêm do aparato estatal, decorrentes do poder de polícia atribuído ao Estado para manter a ordem social. Tais formas de regulação não ofendem o princípio da liberdade individual, desde que tomadas com vista a evitar danos à terceiros (maior felicidade geral) in MILL, John Stuart. Utilitarismo. São Paulo: Hunter Books, 2014. p. 69. Argumento igualmente defendido em THALLER, Richard; SUSTEIN, Cass R. Libertarian paternalism is not an oxymoron. University of Chicago Public Law \& Legal Theory: Working paper, Chicago, n. 43, p. 09, 2003.

40 SUSTEIN, Cass. Why nudge? the politics of libertarian paternalism. Londres: Yale University Press, 2012. p. 163.

41 Inúmeras críticas direcionadas à teoria da racionalidade são feitas a partir de pressupostos behavioristas, por exemplo: STAATS, Arthur W. Behaviorismo social: uma ciência do homem com liberdade e dignidade. Arquivos Brasileiros de Psicologia, São Paulo, v. 32, n. 4, p. 97-116, 1980.

42 MURAMATSU, Roberta; FONSECA, Patrícia. Freedom of choice in a world of boundedly rational agents: remarks about the light paternalistic policy implications of behavioral economics. Disponível em: <http://www.econ.uba.ar/www/institutos/epistemologia/marco_archivos/trabajos_XV_archivos/Muramatsu $\% 20 \mathrm{y} \% 20$ Fonseca $\% 20-\% 20$ Freedom $\% 20$ of $\% 20$ Choice $\% 20$ in $\% 20 \mathrm{a} \%$ 20World \%20of\%20Bounde.pdf>. Acesso em: 17 jan. 2018.

43 KOROBKIN, Russell B.; ULEN, Thomas S. Law and behavioral science: removing rationality assumption from law and economics. California Law Review, v. 88, p. 1138-1144, 2000.

44 KOROBKIN, Russell B.; ULEN, Thomas S. Law and behavioral science: removing rationality assumption from law and economics. California Law Review, v. 88, p. 1138-1144, 2000.

45 JOLLS, Christine et al. A behavioral approach to law and economics. In: SUSTEIN, Cass R. (Coord.). Behavioral law \& economics. New York: Cambridge University Press, 2000. p. 46.

46 THALER, Richard H.; SUNSTEIN, Cass R. Nudge: improving decisions about health, wealth and happiness. London: Penguin, 2008. p. 94.

47 THALER, Richard H. Misbehaving: the making of behavioral economics. New York: Norton \& Company, 2015. p. 323. 


\subsection{A Arquitetura das Escolhas e as Políticas Públicas}

No âmbito das políticas públicas que consideram o comportamento psicológico como elemento fundamental do ato político, ganhou notoriedade o termo anglófono "nudge". O termo "nudge" alcançou destacada relevância dentro do contexto político norte-americano, quando alguns gestores públicos ligados à Behavioural Law and Economics tomaram assento nos setores estratégicos da gestão do então presidente americano Barack Hussein Obama ${ }^{48}$. A tradução não oficial do vocábulo demonstra seu significado: "nudge" pode ser entendido como um "empurrão", um "cutucão", uma espécie de "indicação" não explícita e não vinculativa de opções previamente programadas pelo agente público. Em 2008, o livro "Nudge: o empurrão para escolha certa" $"$, de Cass Sustein e Richard Thaler, consagrou o termo nudge. De forma geral, ele atua como um mecanismo influenciador de escolhas individuais com vista ao incremento do bem-estar em diversos setores sociais, como saúde, educação, finanças e segurança. Um dos exemplos citados no livro refere-se à regulação da disposição de alimentos não saudáveis em escolas primárias nos Estados Unidos. A fim de combater a hábitos alimentares inadequados entre crianças em idade escolar, escolas foram incentivadas a posicionar alimentos saudáveis no campo de visão mediano da altura das crianças, de modo que alimentos não saudáveis ficavam ou muito acima ou muito abaixo do campo de visão, levando as crianças a optar, inconscientemente, pelo consumo de alimentos com melhor condição nutricional ${ }^{50}$.

A partir de então, inúmeros países buscam implementar tais ferramentas no contexto de seus programas políticos procurando mensurar e promover a sensação de bem-estar mediante aplicação de programas políticos nesse sentido ${ }^{51}$. O nudging é um mecanismo sugestivo. Como não é obrigatório, o incentivo funciona como um plano de prévio de persuasão colocado à avaliação do agente no momento da escolha.

Para os teóricos da Behavioural Law and Economics, os agentes econômicos estão envoltos em uma série de armadilhas não declaradas, por isso, compete ao Estado, imbuído de sua missão social de buscar o bem-estar coletivo, ordenar as opções considerando os programas políticos previamente definidos no âmbito das políticas públicas. $\mathrm{O}$ agente econômico, além de estar submetido a um conjunto de informações limitadas, está, totalmente, influenciado por uma série de fatores que conduzem suas escolhas ao nível não ótimo. Para equilibrar o contexto das opções, a Behavioural Law and Economics sugestiona que o gestor das políticas públicas incorpore o papel de um "arquiteto das escolhas".

Ao promover um esclarecimento orientado, a política pública baseada em nudge ambiciona conduzir as opções a um estágio avançado de bem-estar social ${ }^{52}$. Para os comportamentalistas, o desenho de incentivos já é praticado no ambiente social, seja para o bem ou para mal. São inúmeros os exemplos de ofertas de serviços e bens materiais que fazem uso de mecanismos psicológicos para induzir o comportamento dos consumidores, ao menos no ambiente de trocas privadas na economia de mercado.

A arquitetura das escolhas conduzidas pelo Estado regulador preservaria a liberdade de escolha das pes-

48 Notoriamente, o professor americano Cass Sustein, um dos mais proeminentes juristas americanos e cientista no âmbito da Economia e Direito Comportamental, ocupou entre 2009 e 2012 o Office of Information and Regulatory Affairs, da Casa Branca. Outros têm contribuído para esse desenvolvimento, tais como Richard Thaler, Christine Jolls, Alexander Korobkin, Thomas Ulen, Owen Jones ou Jonathan Baron, sendo esse último, inclusive, responsável pela inovadora disciplina de Behavioral Law and Economics na Universidade da Pensilvânia em 2010.

49 Versão brasileira do original lançado em inglês "Nudge: Improving Decisions About Health, Wealth and Happiness".

50 Ver MELLO, Vera Rita Ferreira de; SAPUNAR, Barbara. Nudging for good: o caso do Programa Unidos Por Crianças Mais Saudáveis. Centro de Estudos em Finanças GVcef, 2016-08 Disponível em: <https://bibliotecadigital.fgv.br/dspace/bitstream/ handle/10438/18898/GVcef_Ferreira\%3b\%20Sapunar.pdf?sequence=1\&isAllowed=y >. Acesso em: 10 fev. 2018.

51 Em seu último livro, Daniel Kahneman pontuou que as medições da sensação de bem-estar têm sido, usualmente, praticada em todo o mundo desenvolvido. Estados Unidos, Canadá e Europa contam avançadas técnicas de pesquisa em larga escala. Khaneman citou a pesquisa Gallup World Poll (Gallup-Healthways Well-Being Index), com levantamentos simultâneos em mais de 150 países sobre como as pessoas julgam as condições da própria vida e os fatores circunstanciais que as levam a pensar como pensam, como saúde física, afetividade familiar, condições financeiras etc. Consultar KAHNEMAN, Daniel. Rápido e devagar. Rio de Janeiro: Objetiva, 2012. p. 494.

52 THALER, Richard H. Misbehaving: the making of behavioral economics. New York: Norton \& Company, 2015. p. 255. 
soas enquanto são conduzidas para incrementar sua condição de bem-estar. Evitar os riscos do tabagismo, fazer opções alimentares saudáveis, poupar para a terceira idade, fazer exercícios diários etc. O objetivo central é promover escolhas melhores e, por consequência, obter melhores resultados coletivamente. Para Roberta Muramatsu e Patrícia Fonseca ${ }^{53}$, as políticas que consideram a arquitetura das escolhas uma alternativa viável são vitais para o incremento do bem-estar social. Ajustes de programas que contemplem mecanismos indutivos de comportamento, como disposição de informações em ordem de interesse, incentivos comportamentais para a tomada de decisões, contrapartidas financeiras para a tomada de comportamentos considerados ótimos são alguns modelos que podem ser usados pelo gestor público para conduzir o comportamento dos agentes econômicos.

Ocorre, porém, que nenhuma política pública é levada a efeito sem antes deflagrar certo grau de conflito entre posições antagônicas, embates ideológicos ou choque de interesses. No caso do behaviorismo não é diferente. Ao fazer uso em larga escala dos instrumentos normativos com base em mecanismos comportamentais, as políticas públicas formuladas com base na ciência econômica comportamental são completamente diferentes dos tradicionais instrumentos de coeração pura e explícita, caracteristicas das normas jurídicas clássica elaboradas com base no Poder de Polícia.

No caso da Economia Comportamental, busca-se, por meio da influêcia das escolhas, preservar certo grau de liberdade dentro de um quadro predefinido de opções, de baixo custo e impacto reduzido ${ }^{54}$, sempre com vistas a melhorar a condição de vida das pessoas, que, por essa mesma liberdade, poderiam num ambiente sem influência tomar uma decisão ruim.

Residem nesse específico ponto as críticas daqueles que se opõem à utilização da Economia Comportamental como ferramenta programática do bem-estar social. Ao predefinir uma quadro de opções já articuladas, o Estado induz, ilegalmente, os comportamentos de forma obscura, uma vez que prescinde da autonomia da vontade individual, da declaração consentida e da manifestação inequívoca de intenções. Uma vez que as opções já estão previamente definidas pelo gestor público, reduzindo o campo da liberdade das escolhas, as pessoas já não gozam mais da livre escolha, do "direito de errar" e aprender com o próprio erro $^{55}$. Assim, o conflito ético está localizado, justamente, nessa parodaxal missão do Direito e da Economia Comportamental: ampliar a liberdade de escolha, limitando as livres escolhas do agente econômico.

Em inúmeras situaçãos, a arquitetura dos incentivos pode ser acusada de não respeitar as escolhas dos agentes econômicos, levantando questionamenos de natureza moral e ética ${ }^{56}$. Em alguns casos de nudging, o planejador central prescinde da escolha plena e consciente ${ }^{57}$.

No plano jurídico político institucional, a vinculação de opções políticas à instituição de metas, diretrizes ou princípios, por meio das espécies jurídico-normativas ${ }^{58}$, com o intuito de promover a redução das

53 MURAMATSU, Roberta; FONSECA, Patrícia. Um enigma do comportamento do consumidor no Brasil: análise comportamental do consumo procrastinado em um cenário inflacionário. In: ENCONTRO DA ANPAD, 32., Rio de Janeiro, 2008. p. 8.

54 SUSTEIN, Cass R. The ethics of influence. New York: Cambridge University Press, 2017. p. 98.

55 FERGUSIN, Andrew. Nudge, nudge, wink wink: behavioral rconomics - The Governing Theory of Obama's Nanny State. Time Magazine, n. 19, abr. 2010, em que o Autor aponta fortes críticas à administração de Barack Obama como o "dream team" do comportamentalismo, que realizaria os desejos de transformação silenciosa e paternalista da sociedade americana. Disponível em: <http://www.weeklystandard.com/nudge-nudge-wink-wink/article/433737>. Acesso em: 09 dez. 2017.

56 EPSTEIN, Richard. Behavioral economics: human errors and market corrections. University of Chicago Law Review, Chicago, n. 73.1, p. 111-132, 2006.

57 BOWLES, Samuel. The moral economy, why good incentives are no substitue for good citizens. New York: Yale University Press, 2016.

58 Dworkin esclarece que as normas constitucionais são o gênero das espécies normativas regras, princípios e políticas (policies). Sustenta o autor que, com certa frequência, o termo princípio é utilizado de modo genérico, isto é, projetado de maneira negativa, representando todo o conjunto de padrões normativos que não são regras. Inicialmente, há que se apontar uma distinção mais apurada entre princípios e políticas. Dworkin assevera que política é aquele tipo de padrão que estabelece um objetivo a ser alcançado, em geral uma melhoria em algum aspecto econômico, político ou social da comunidade (ainda que certos objetivos sejam negativos pelo fato de estipularem que algum Estado atual deve ser protegido contra mudanças adversas). Já princípio pode ser tido como um padrão que deve ser observado, não porque vá promover ou assegurar uma situação econômica, política ou social considerada desejável, mas porque é uma exigência da justiça ou equidade ou alguma outra dimensão da moralidade. Assim, o padrão 
desigualdades sociais, por exemplo, é estabelecido por um consenso mínimo a ser seguido pela maioria, especialmente para a formulação de políticas específicas ${ }^{59}$. Assim, falar em consenso no âmbito das políticas públicas implica reconhecer a presciência dos instrumentos políticos e econômicos que deverão ser aplicados para a consecução das finalidades constitucionais, o que poderia, ao menos em tese, conflitar com qualquer política pública que opere no campo da inconsciência dos indivíduos. No caso, o principal risco à liberdade e à autonomia individual é o indiscriminado uso política do behaviorismo como elemento normativo, uma vez que não exigem o consenso mínimo ou acordo democrático, como nos casos das tradicionais normas coercitivas ${ }^{60}$. Além dessa inexorável vinculação das políticas públicas aos fins constitucionais, fundadas nos valores republicano da autonomia e liberdade individual, há duras críticas sobre o papel do Estado para construir políticas que, ao fim e ao cabo, retiram do indivíduo a liberdade de escolha, uma vez que as finalidades a serem alcançadas por esse mecanismo (nudge) de intervenção no domínio econômico são previamente "desenhadas" pelo agente regulador.

O papel do Estado como ente regulador tem relação direta com o comportamento dos agentes no ambiente socioeconômico. Agir de acordo com os incentivos gerados pelo Poder Público revela nada mais que um processo pelo qual uma organização ou indivíduo busca maximizar a função utilidade pelo ajustamento das suas preferências ${ }^{61}{ }^{62}$. A Economia Comportamental diverge desse último ponto. Para os comportamentalistas, firmas e pessoas não agem sempre conscientemente, razão pela qual Estado Regulador pode ser chamado a "empatar" o jogo dos incentivos com a políticas de intervenção comportamental.

Colocam-se inúmeros questionamentos acerca dos limites do Estado na interferência do domínio privado. A relevância do debate que envolve a Economia Comportamental e seus mecanismos na busca pelo incremento do bem-estar social constitui, possivelmente, uma das mais polêmicas formas de intervenção do Estado no domínio econômico, especialmente a partir da virada do Século XX. A relevância do desgin comportamental em Políticas Públicas foi, inclusive, distinguida com o Prêmio de Ciências Econômicas em Memória de Alfred Nobel de 2017. O cientista comportamental Richard Thaler ${ }^{63}$, responsável por incorporar os pressupostos da psicologia aos mecanismos de regulação do comportamento econômico, foi escolhido como o prêmio do ano. Eis a importância de considerar elemento cognitivo-comportamental como variável indispensável para condução dos comportamentos. Essa nova forma de avaliar a ingerência do Estado no domínio econômico introduz, no debate científico, respostas oriundas de outros campos da ciência, sobremaneira quando um dos objetivos do programa jurídico-político é alcançar o bem-estar social. Por trás dos posicionamentos a favor ou contra a adoção de tais medidas, uma ampla discussão se faz necessária: sobre os limites éticos e morais que circundam a aplicação do nudging como forma de efetivar as mudanças comportamentais.

que estabelece que o IDH deve ser majorado é uma política e o padrão segundo o qual nenhum homem deve beneficiar-se de seus próprios delitos é um princípio. A distinção se torna problemática, entretanto, se tomarmos um princípio como expressão de um objetivo social (é objetivo de uma sociedade que nenhum homem se beneficie de seu próprio delito), ou interpretarmos uma política como resultado de um princípio, ou seja, o princípio de que o objetivo que a contém é meritório. Os princípios são proposições que descrevem direitos; as políticas são proposições que descrevem objetivos. DWORKIN, Ronald. Levando os direitos a sério. São Paulo: M. Fontes, 2007. p. 36.

59 BARCELLOS, Ana Paula de. Neoconstitucionalismo, direitos fundamentais e controle das políticas públicas. Revista de Direito Administrativo, Rio de Janeiro, n. 240, p. 83-103, abr./jun. 2005.

60 SARLET, Ingo Wolfgang. A eficácia dos direitos fundamentais. Porto Alegre: Livraria do Advogado, 2009. p. 364.

61 RIBEIRO, Márcia Carla Pereira. Racionalidade limitada. In: RIBEIRO, Márcia Carla Pereira; KLEIN, Vinicius (Coord.). O que é análise econômica do direito: uma introdução. 2. ed. Belo Horizonte: Fórum, 2016. p. 64.

62 Williamson defende a existência de três tipos de racionalidade: forte, semiforte ou limitada e fraca. Assim, a racionalidade atribuída à teoria econômica neoclássica é classificada como racionalidade forte, que supõe o pleno conhecimento de todos os custos de transação pelo agente econômico. WILLIAMSON, O. E. The economic institutions of capitalism. New York: Free Press, 1985. 63 "Richard H. Thaler foi o ganhador do Prêmio Nobel de Ciências Econômicas em 2017 por suas contribuições para a Economia Comportamental. Thaler estuda economia e finanças comportamentais, bem como a psicologia da tomada de decisões. Seu foco de investigação são as implicações quanto ao pressuposto econômico padrão da racionalidade econômica, onde supostamente todos agentes são racionais e egoístas. Richard Thaler é o diretor do Center for Decision Research e co-diretor (com Robert Shiller) do Behavioral Economics Project no National Bureau of Economic Research." Tradução livre da biografia publicada no website da Universidade de Chicago. Disponível em: <https://www.chicagobooth.edu/faculty/directory/t/richard-h-thaler>. Acesso em: 10 dez. 2017. 
Por fim, os pressupostos teóricos desse debate devem compreender essa modificação de paradigmas sobre o conceito de racionalidade. Quando as políticas públicas não cogitavam fazer uso da tecnologia comportamental, o modelo sobe os quais estavam fixadas suas bases tinham em conta um indivíduo de preferências estáveis, completamente consciente de suas ações. Com a contestação do paradigma da racionalidade, e as recentes descobertas da Teoria da Prospecção e suas derivações, esse paradigma foi completamente alterado. Essa modificação foi determinante para o acolhimento de mecanismos comportamentais na formulação de políticas públicas. Pode-se afirmar que existe, hoje, um campo jurídico autônomo de proteção dos indivíduos. Uma ampliação da tutela das más-escolhas. Esse novo campo jurídico de atuação do Estado pressupõe que os agentes sociais não são racionais, e às vezes tomam decisões prejudiciais e em desacordo com o que realmente escolheriam se não estivessem sob a influência dos processos mentais enviesados.

\section{Considerações finais}

A modificação dos paradigmas da racionalidade econômica provocou uma nova forma de ver o indivíduo como destinatário final de políticas públicas. Isso decorreu da experiência de adoção das análises comportamentalistas em relação à formulação dos programas políticos, a partir da virada do Século XX. Da mesma forma, houve a ampliação da atuação do Estado em setores da vida privada que antes não eram afetados pelas políticas públicas. O nudge foi adotado em ambientes de escolhas estritamente particulares, com vistas a alterar o comportamento dos indivíduos e incrementar o seu bem-estar social.

Não obstante, a regulação dos comportamentos com base na Economia Comportamental carece de limites claros e específicos. Historicamente, escolhas individuais que conduzem as pessoas ao fracasso ou à ruína nem sempre demandaram a intervenção estatal. Mesmo assim, em inúmeros outros casos, a correção dos comportamentos indesejados é um convite à intervenção reguladora do ente público. Por isso, a abrangência do behaviorismo e o desenho dos incentivos espalharam-se por campos diversos do Direito, como no Direito do Consumidor, nas leis antitruste, na segurança alimentar e na preservação de recursos ambientais. Enfim, muito há que se discutir sobre as hipóteses em que é desejável, ou juridicamente legítima, a intervenção do Estado no domínio socioeconômico. Se, por um lado, as escolhas dos agentes econômicos não detêm plena racionalidade como se pressupunha, por outro, há o risco da entrega de parcela significativa da autonomia individual ao Estado regulador. No caso brasileiro, nada foi suscitado sobre políticas públicas desenhadas com mecanismos de Economia Comportamental. $\mathrm{O}$ debate pode ser incipiente num primeiro momento, sobretudo quando se acrescenta a dimensão normativa aos mecanismos comportamentais. Entretanto, como determina nossa ordem econômica constitucional, o Estado tem o dever de assegurar a todos existência digna.

Por essa razão, acredita-se, abre-se a oportunidade de se provocar a reflexão sobre o potencial desse método de abordagem, também, na esfera jurídica, aproveitando-se alguns elementos de Economia Comportamental com vistas a aferir maior efetividade às determinações constitucionais.

\section{REFERÊNCIAS}

AKERLOFF, George; SHILLER, Robert. O espirito animal. Rio de Janeiro: Elsevier, 2009.

ARAÚJO, Fernando. Análise económica do direito: programa e guia de estudo. Lisboa: Almedina, 2008.

ARIELY, Dan. Positivamente irracional. Rio de Janeiro: Elsevier, 2010.

BARCELLOS, Ana Paula de. Neoconstitucionalismo, direitos fundamentais e controle das políticas públi- 
cas. Revista de Direito Administrativo, Rio de Janeiro, n. 240, p. 83-103, abr./jun. 2005.

BARON, Jonathan. Biases in the quantitative measurement of values for public decisions. Psychological Bulletin, Filadélfia, n. 122, p. 72-88, 1997.

BOWLES, Samuel. The moral economy: why good incentives are no substitue for good citizens. New York: Yale University Press, 2016.

BRUNI, Luigino; SUNGDEN, Robert. The road not taken: how psychology was removed from economics, and how it might be brought back. The Economic Journal, Rio de Janeiro, v. 117, n. 516, p. 146-173, 2007.

CÁRDENAS, Juan Camilo. Groups, commons and regulations: experiments with villagers and students in Colombia. In: AGARWAL, Bina; VERCELLI, Alessandro. (Ed.). Psychology, rationality and economic behavior. New York: Palgrave MacMillan, 2005.

DAVIDAI, Shai; GILOVICH, Thomas; ROSS, Lee D. The meaning of default options for potential organ donors. Proceedings of the National Academy of Sciences, v. 109, n. 38, p. 15201-15205, sep. 2012.

DWORKIN, Ronald. Levando os direitos a sério. São Paulo: M. Fontes, 2007.

EPSTEIN, Richard. Behavioral economics: human errors and market corrections. University of Chicago Law Review, Chicago, n. 73.1, p. 111-132, 2006.

FERGUSIN, Andrew. Nudge, nudge, wink wink: behavioral economics - The Governing Theory of Obama’s Nanny State. Time Magazine, n. 19, abr. 29, 2010. Disponível em: < http://www.weeklystandard.com/ nudge-nudge-wink-wink/article/433737>. Acesso em: 28 maio 2018.

FISHER, Irwing. The theory of interest. New York: Macmillan, 1930.

JEVONS, Willian S. The theory of political economy. Londres: McMillian, 1888.

JOLLS, Christine et al. A behavioral approach to law and economics. In: SUSTEIN, Cass R. (Coord.). Behavioral law \& economics. New York: Cambridge University Press, 2000.

KAHNEMAN, Daniel. Rápido e devagar. Rio de Janeiro: Objetiva, 2012.

KOROBKIN, Russell B.; ULEN, Thomas S. Law and behavioral science: removing rationality assumption from law and economics. California Law Review, v. 88, p. 1138-1144, 2000.

LEWIN, Shira B. Economics and psychology: lessons for our own day from the early twentieth century. Journal of Economic Literature, v. 34, n. 3, p. 1293-1323, set. 1996.

LOHRENZ, Terry; MONTAGUE, P. Read. Neuroeconomics: what neuroscience can learn from economics. In: LEWIS, Alan. (Org.). The Cambridge handbook of psychology and economic behaviour. Cambridge: Cambridge University Press, 2008.

MANDLER, Michael. Dilemmas in economic theory: persisting foundational problems in microeconomics. New York: Oxford, 1999.

MARSHAL, Alfred. Principles of economics. 8. ed. Londres: McMillian, 1920.

MELLO, Vera Rita Ferreira de; SAPUNAR, Barbara. Nudging for good: o caso do programa unidos por crianças mais saudáveis. Centro de Estudos em Finanças GVcef, 2016. Disponível em: <https://bibliotecadigital.fgv.br/dspace/bitstream/handle/10438/18898/GVcef_Ferreira\%3b\%20Sapunar. pdf ?sequence $=1 \&$ isAllowed $=\mathrm{y}>$. Disponível em: 28 maio 2018 .

MILL, John Stuart. Utilitarismo. São Paulo: Hunter Books, 2014.

MONROY, Daniel. Nudges y decisiones inconscientes: sesgo de status quo y políticas públicas em Colombia. Revista Desafios, Bogotá, v. 29, n. 1, p. 211-247, dic. 2016. 
MURAMATSU, R. The death and resurrection of economics with psychology: remarks from a methodological standpoint. Revista de Economia Política, São Paulo, v. 29, p. 62-81, jan./mar. 2009.

MURAMATSU, Roberta; FONSECA, Patrícia. Freedom of choice in a world of boundedly rational agents: remarks about the light paternalistic policy implications of behavioral economics. Disponível em: <http://www. econ.uba.ar/www/institutos/epistemologia/marco_archivos/trabajos _XV_archivos/Muramatsu\%20 y $\% 20$ Fonseca $\% 20-\% 20$ Freedom $\% 20$ of $\% 20$ Choice $\% 20$ in $\% 20 \mathrm{a} \%$ 20World $\% 20$ of $\% 20$ Bounde.pdf $>$. Acesso em: 28 maio 2018.

MURAMATSU, Roberta; FONSECA, Patrícia. Um enigma do comportamento do consumidor no Brasil: análise comportamental do consumo procrastinado em um cenário inflacionário. In: ENCONTRO DA ANPAD, 32., 2008, Rio de Janeiro.

NEVES, Antônio Francisco Frota; SANTANA, Hector Valverde. A intervenção direta e indireta na atividade econômica em face da ordem jurídica brasileira. Revista Brasileira de Políticas Públicas, Brasília, v. 7, n. 2, p. 332-348, ago. 2017.

PRADO, Eleutério F. S. A ortodoxia neoclássica. Estudo Avançados, São Paulo, v. 15, n. 41, jan./abr. 2001.

RIBEIRO, Márcia Carla Pereira. Racionalidade limitada. In: RIBEIRO, Márcia Carla Pereira; KLEIN, Vinicius (Coord.). O que é análise econômica do direito: uma introdução. 2. ed. Belo Horizonte: Fórum, 2016.

SAMUELSON, Paul. Fundamentos da análise econômica. São Paulo: Nova Cultural, 1998.

SANTOS, Ana Cordeiro dos. The social epistemology of experimental economics. New York: Routledge, 2009.

SARLET, Ingo Wolfgang. A eficácia dos direitos fundamentais. Porto Alegre: Livraria do Advogado, 2009.

SEN, A. Desenvolvimento como liberdade. São Paulo: Cia. das Letras, 2000.

SHAFIR, Eldar. The behavioral foundations of public policy. Princeton: Princeton, 2012.

SIMON, H. Alternative visions of rationality. In: ARKES, H.; HAMMONDS, K. (Coord.). Judgement and decision making. Cambridge: Cambridge University Press, 1986.

SOWELL, Thomas. Conflito de visões: origens ideológicas das lutas políticas. São Paulo: É Realizações, 2011.

SUSTEIN, Cass. The ethics of influence. New York: Cambridge University Press, 2017.

SUSTEIN, Cass. Why nudge? the politics of libertarian paternalism. Londres: Yale University Press, 2012.

THALER, Richard H. Misbehaving: the making of behavioral economics. New York: Norton \& Company, 2015.

THALLER, Richard; SUSTEIN, Cass R. Libertarian paternalism is not an oxymoron. University of Chicago Public Law \& Legal Theory: Working paper, Chicago, n. 43, p. 09, 2003.

THALER, Richard H.; SUNSTEIN, Cass R. Nudge: improving decisions about health, wealth and happiness. London: Penguin, 2008.

TVERSKY, Amos; KAHNEMAN, Daniel. Judgement under uncertainty: heuristics and biases. Science, v. 185, n. 4157, sep. 1974.

WILLIAMSON, O. E. The economic institutions of capitalism. New York: Free Press, 1985. 
Para publicar na revista Brasileira de Políticas Públicas, acesse o endereço eletrônico www.rbpp.uniceub.br

Observe as normas de publicação, para facilitar e agilizar o trabalho de edição. 